\title{
DESLIGNIFICAÇÃO DOS RESÍDUOS AGRÍCOLAS DA CULTURA DA MAMONA PARA PRODUÇÃO DE CELULOSE E PAPEL ${ }^{(1)}$
}

\footnotetext{
ANÍSIo AZZINI (2), Seção de Plantas Fibrosas, ÂNGELo SAVY FILHO, Seção de Oleaginosas, ANTONIO LUIZ DE BARROS SALGADO, Segão de Plantas Fibrosas, e FRANCISCA ZULEIDE ARNALDI (3), Instituto Agronômico.
}

\section{RESUMO}

Foram estudados os resíduos agrícolas da cultura da mamona (cultivar IAC-80), visando a sua conversão em celulose para papel, mediante os processos alcalinos soda e sulfato. A quantidade estimada desse material nas áreas dos experimentos foi 17,20 e 26t/ha, respectivamente, para as regiões de Campinas, Tatuí e Tietê. A densidade básica dos caules e ramos da mamona em comparação com as madeiras é baixa $\left(0,228 \mathrm{~g} / \mathrm{cm}^{3}\right)$. O estudo micrométrico mostrou que as fibras do líber são extremamente longas $(5,51 \mathrm{~mm})$, contrastando com as fibras curtas do lenho $(0,87 \mathrm{~mm})$. Os valores obtidos para as diversas características tecnológicas estudadas evidenciam a possibilidade técnica de utilizar esse residuo agricola para produção de celulose e papel, ressaltando que seu principal inconveniente é o elevado teor de medula $(21,17 \%)$. A fração medular, por não ser fibrosa, influi negativamente no rendimento em celulose e no consumo de reagentes químicos.

\section{INTRODUÇÃO}

Em nosso País, tem grande significado econômico o cultivo da mamona, visando à produção de óleo, principalmente pelas suas amplas possibilidades de utilização nas indústrias química, têxtil, eletrônica,

(1) Recebido para publicação a 16 de junho de 1983.

(2) Com bolsa de suplementação do CNPq.

(3) Estagiária da Seção de Plantas Fibrosas. 
mecânica e automotiva. Em 1982, a área de plantio com mamona atingiu 470.000 hectares, produzindo 119.000 toneladas de óleo (10). Essa produção, que representou $35 \%$ da mundial, possibilitou ao Brasil manter a hegemonia no mercado internacional.

A cultura da mamona, com um ciclo vegetativo de aproximadamente 240 dias, fornece, além do óleo, grande quantidade de resíduos agricolas fibrosos que podem ser convertidos em celulose para papel (2). Normalmente, as folhas, ramos e caules da mamona são destruídos (queimados), visando preparar convenientemente o terreno para novos plantios. Esse procedimento, que representa um desperdício de fitomassa, não se justifica nos dias atuais, pois, não apresentando utilização econômica, esse material deve ser incorporado ao solo, cujas características físicas, químicas e biológicas melhorarão.

A indústria de celulose e papel está cada vez mais preocupada com o futuro suprimento de matérias-primas fibrosas para atender à crescente demanda do setor. Essa preocupacão se baseia na escassez e na progressiva valorização da madeira, que representa mais de $90 \%$ da matéria-prima nacional convertida em celulose e papel. Estimativas recentes demonstram que, em 1988, ocorrerá um déficit de 11,7 milhōes de estéreos de madeiras folhosas e resinosas, fornecedores, respectivamente, de fibras curtas e longas (4). A situação é mais crítica para as madeiras coniferas ou resinosas, cuja importação, em 1981, atingiu 65.000 toneladas de celulose, que foram empregadas na fabricação de papéis para jornal e embalagem (5).

Dentre as várias opçōes para suprir ou aumentar a oferta de matérias-primas fibrosas para a indústria de celulose e papel, pode-se destacar, além da expansão das áreas reflorestadas, a utilização das espécies não-arbóreas, incluindo os resíduos agrícolas. No Brasil, apesar de sua grande possibilidade de emprego pela indústria papeleira, esses materiais permanecem numa posição de absoluta inferioridade, prisicipalmente por falta de maior motivação econômica, aliada ao desconhecimento tecnológico de aproveitamento. A potencialidade dos resíduos agricolas pode ser evidenciada, considerando que sua produção nas cuituras de milho, arroz, algodão e mamona, no Estado de São Paulo, atingiu, em 1982, cinco milhōes de toneladas, correspondendo a $41,6 \%$ de déficit de màdeiras estimado para 1988.

Os estudos conduzidos por NIESCHLAG (9) ressaltam que as fibras liberianas de mamona (Ricinus communis L.) são extremamente longas, sendo possível usá-las como fibras têxteis para indústria de cordoalha. AZZINI et alii (2) observaram que o comprimento médio das fibras, em três cultivares de mamona, variou de 6,4 a $7,4 \mathrm{~mm}$ para as do líber e de 0,95 a $1,00 \mathrm{~mm}$ para as do lenho.

O objetivo desse estudo foi determinar as características tecnológicas das pastas celulósicas obtidas pelos processos soda e sulfato a partir dos resíduos fibrosos da cultura da mamona. 


\section{MATERIAL E MétOdOS}

Foram utilizados os resíduos agrícolas (parte aérea das plantas, com exceção das folhas) da cultura da mamona (cultivar IAC-80) provenientes de um experimento conduzido em 1982 no Centro Experimental de Campinas, pela Seção de Oleaginosas.

A quantidade dos resíduos agrícolas fibrosos produzida por unidade de área foi determinada em três locais diferentes (Tietê, Tatuí e Campinas), amostrando, para cada um deles, 50 plantas típicas e homogêneas, tomadas inteiramente ao acaso na área de cada experimento.

A densidade básica do material fibroso em estudo foi determinada pelo método do máximo teor de umidade ( $\boldsymbol{\gamma})$. Os teores de líber, lenho e medula foram calculados pela relação percentual entre o peso de cadá fração e o peso inicial da amostra seca em estufa a $50^{\prime} \mathbf{C}$. O estudo micrométrico das fibras foi realizado em amostras de líber e lenho, maceradas em soluçāo contendo ácido acético glacial $(50 \%)$, água oxigenada a 130 volumes $(30 \%)$ e água destilada (20\%). Essa solução foi mantida em ebulição sob condensador até completa individualização dos elementos anatômicos. Após coloração, as fibras foram dimensionadas quanto ao comprimento, diâmetro do lúmen $€$ espessura da parede celular, em microscópio provido de ocular especial com filamento móvel. A largura das fibras foi calculada indiretamente, somande-se o valor do diâmetro do lúmen e duas vezes a espessura da parede ceilular. O comprimento intermediário das fibras, obtido quando se misturam fibras longas do líber com fibras curtas do lenho, foi estimado conforme método preconizado por NIESCHLAG et alii (9). As relaçōes existentes entre as dimensôes das fibras, consideradas como importantes parâmetros relacionados com a qualidade da celulose, foram determinadas segundo MILANEZ \& FOELKEL (8).

As análises quimicas do material em estudo foram realizadas segundo normas da ASSOCIAÇĀO TÉCNICA BRASILEIRA DE CELULOSE E PAPEL (1). O teor de celulose no lenho e líber foi calculado pela relação percentual entre o peso da celulose e o da amostra seca em estufa a $60^{\circ} \mathrm{C}$. As pastas celulósicas foram obtidas por meio dos processos alcalinos soda e sulfato, com três niveis de concentração dos reagentes químicos, conforme as condições apresentadas no quadro 1.

A conversão do material fibroso em pastas celulósicas foi realizada em digestor rotativo (2rpm) com capacidade para 20 litros, aquecido eletricamente, provido de manômetro e termômetro. Após a digestão, as pastas celulósicas foram lavadas e depuradas para calcular os rendimentos depurados e os teores de rejeitos, conforme métodos preconizados pela ASSOCIAÇÃO TÉCNICA BRASILEIRA DE CELULOSE E PAPEL (1). Os rendimentos totais foram obtidos pela soma dos rendimentos depurados e teores de rejeitos. O grau de deslignificação das pastas celulósicas foi determinado pelo número Kappa, segundo a ASSO- 
CIAÇÃO TÉCNICA BRASILEIRA DE CELULOSE E PAPEL (1), mediante o qual se calculou o teor de lignina nas pastas celulósicas, conforme indicado por SAGRISTÃ (11).

QUADRO 1. Condições de đeslignificação para os processos sulfato e soda

\begin{tabular}{|c|c|c|c|c|c|c|}
\hline \multirow{2}{*}{ Condições de deslignificação } & \multicolumn{3}{|c|}{ Sulfato } & \multicolumn{3}{|c|}{ Soda } \\
\hline & 1 & 2 & 3 & 4 & 5 & 6 \\
\hline Álcali ativo - $\% \mathrm{Na}, \mathrm{O}$ & 18 & 20 & 22 & - & - & -- \\
\hline Sulfidez $-\%$ & 20 & 20 & 20 & 一 & - & - \\
\hline Soda $-\% \mathrm{Na}_{2} \mathrm{O}$ & - & 一 & 一 & 18 & 20 & 22 \\
\hline Relação licor/material & $5 / 1$ & $5 / 1$ & $5 / 1$ & $5 / 1$ & $5 / 1$ & $5 / 1$ \\
\hline Concentração do licor $-\% \mathrm{Na}_{2} \mathrm{O}$ & 3,6 & 4,0 & 4,4 & 3,6 & 4,0 & 4,4 \\
\hline Temperatura máxima - ${ }^{\circ} \mathrm{C}$ & 160 & 160 & 160 & 160 & 160 & 160 \\
\hline Tempo até temp. máxima - min & 105 & 105 & 105 & 105 & 105 & 105 \\
\hline Tempo na temp. máxima - min & 60 & 60 & 60 & 60 & 60 & 60 \\
\hline
\end{tabular}

As propriedades físico-mecânicas das pastas celulósicas, relacionadas com grau de refinação, comprimento de auto-ruptura, alongamento, indice de rasgo e de arrebentamento e peso especifico aparente, foram determinadas pelas normas da ASSOCIAÇĀO TÉCNICA BRASILEIRA DE CELULOSE E PAPEL (1), em folhas e testes preparados em formador Regmed FFS/2. A refinação foi realizada em moinho Regmed tipo $\mathrm{MJ} / \mathrm{K} 6$ a uma consistência de massa de $6 \%$.

O delineamento estatístico empregado para comparar as características das pastas celulósicas obtidas pelos processos soda e sulfato foi de parcelas subdivididas. As comparaçōes entre os pares de médias foram feitas pelo teste de Duncan ao nível de $5 \%$.

\section{RESULTADOS E DISCUSSÃO}

A quantidade de resíduos agrícolas fibrosos estimada para a cultura da mamona (cultivar IAC-80) foi 17, 20 e 26t/ha, respectivamente, para as regiōes de Campinas, Tatuí e Tietê. Essa variação na quantidade do material fibroso foi devida, principalmente, ao peso das plantas, que na região de Tietê foi maior, como se pode obzervar no quadro 2.

Embora o cultivar em estudo seja de porte alto, adaptado à colheita manual de sementes, sua produção de fitomassa fibrosa (caules e ramos) foi semelnante àquelas estimadas por AZZINI et alii (2) para os cuitivares Guarani, Borracha e Preta. A elevada produção de fitomassa por unidade de área evidencia sua potencialidade de utilização pela indús- 
tria de celulose e papel. Evidentemente, as caracteristicas físicas, químicas e anatômicas dessa matéria-prima devem ser determinadas para se conhecer sua viabilidade tecnológica. Os valores obtidos para densidade básica e teores de líber (casca), lenho e medula, são apresentados no quadro 3 .

QUADRO 2. Dimensões das plantas e quantidade de residuos agrícolas na cultura da. mamona (1)

\begin{tabular}{|c|c|c|c|c|c|}
\hline & Local & $\begin{array}{l}\text { Altura da } \\
\text { planta }\end{array}$ & $\begin{array}{c}\text { Diâmetro } \\
\text { basal }\end{array}$ & $\begin{array}{l}\text { Peso da } \\
\text { planta }\end{array}$ & $\begin{array}{l}\text { Quantidade } \\
\text { de resíduo }\end{array}$ \\
\hline \multirow[t]{5}{*}{ Estação } & Experimental de Tietê & m & $\mathrm{cm}$ & $\mathrm{kg}$ & t/ha \\
\hline & Média & 2,63 & 5,74 & 5,32 & 26 \\
\hline & s & 0,25 & 1,06 & 2,10 & - \\
\hline & $s(\bar{x})$ & 0,03 & 0,14 & 0,29 & - \\
\hline & c.v. $(\%)$ & 9,77 & 18,42 & 39,53 & 一 \\
\hline \multirow[t]{5}{*}{ Estação } & Experimental de Tatui & & & & \\
\hline & Média & 2,79 & 4,83 & 4,04 & 20 \\
\hline & $\mathbf{s}$ & 0,24 & 0,87 & 1,87 & 一 \\
\hline & $\mathrm{s}(\overline{\mathrm{x}})$ & 0,03 & 0,11 & 0,25 & - \\
\hline & c.v. $(\%)$ & 8,79 & 18,13 & 46,32 & - \\
\hline \multirow[t]{5}{*}{ Estação } & Experimental de Campinas & & & & \\
\hline & Média & 2,58 & 4,95 & 3,45 & 17 \\
\hline & $\mathbf{s}$ & 0,12 & 0,52 & 0,90 & - \\
\hline & $\mathbf{s}(\bar{x})$ & 0,01 & 0,07 & 0,12 & - \\
\hline & c.v. $(\%)$ & 4,83 & 10,54 & 26,13 & - \\
\hline
\end{tabular}

(1) Médias de 50 plantas. $\mathbf{s}=$ desvio-padrão. $\mathbf{s ( \overline { x } )}=$ erro-padrão da média.

c.v. = coeficiente de variação.

QUADRO 3. Densidade básica e teores de liber (casca), lenho e medula nos resíduos agrícolas da cultura da mamona

\begin{tabular}{lcccc}
\hline Valor & $\begin{array}{c}\text { Densidade } \\
\text { básica }\end{array}$ & $\begin{array}{c}\text { Liber } \\
\text { (casca) }\end{array}$ & Lenho & Medula \\
\hline & $\mathbf{g} / \mathrm{cm}^{3}$ & $\%$ & $\%$ & $\%$ \\
Mínimo & $\mathbf{0 , 1 6 2}$ & $\mathbf{1 1 , 4 2}$ & $\mathbf{7 4 , 7 2}$ & $\mathbf{1 0 , 9 9}$ \\
Médio & 0,228 & 17,30 & 82,70 & $\mathbf{2 1 , 1 7}$ \\
Máximo & 0,326 & $\mathbf{2 5 , 2 8}$ & $\mathbf{8 8 , 5 8}$ & $\mathbf{3 1 , 0 7}$ \\
$\quad$ s & 0,04 & 3,58 & 3,58 & $\mathbf{6 , 2 0}$ \\
c.v. \% & 20,45 & 20,73 & 4,34 & $\mathbf{2 9 , 2 8}$ \\
\hline
\end{tabular}

s = desvio-padrão. c.v. = coeficiente de variação. 
A densidade básica desse material fibroso foi relativamente baixa $\left(0,228 \mathrm{~g} / \mathrm{cm}^{3}\right)$ em comparação com a das madeiras tradicionalmente empregadas na produção de celulose e papel: eucaliptos $\left(0,530 \mathrm{~g} / \mathrm{cm}^{3}\right.$ e pinus $\left(0,412 \mathrm{~g} / \mathrm{cm}^{3}\right)(\boldsymbol{\gamma})$. A densidade básica é uma das mais importantes características tecnológicas da matéria-prima fibrosa, relacionada não só com as propriedades físico-mecânicas do papel produzido, mas, também, com os aspectos econômicos da colheita, transporte, estocagem e rendimento industrial ds equipamentos.

No quadro 3, pode-se observar que os teores de líber, lenho e medula foram, respectivamente, $17,30 \%, 82,70 \%$ e $21,17 \%$. Os teores de líber e lenho podem ser considerados normais para esse tipo de material, sendo semelhantes àqueles obtidos com outros cultivares de mamona (2). A fração medular, presente na região central dos caules e ramos, por não ser fibrosa, influi negativamente na produção de celulose, pois, além de reduzir o rendimento de conversão, aumenta o consumo de reagentes químicos.

O estudo micrométrico das fibras desse resíduo agrícola (Quadro 4) confirmou que o líber e o lenho fornecem, respectivamente, fibras extremamente longas $(5,51 \mathrm{~mm})$ e curtas $(0,87 \mathrm{~mm})$, em cornparação com as fibras das madeiras de Pinus oocarpa $(3,8 \mathrm{~mm})$ (6) e Eucaliptus saligna $(0,94 \mathrm{~mm})(\boldsymbol{y})$. Por serem extremamente longas, as liberianas podem ser utilizadas como fibras têxteis na indústria de cordoalha, segundo Floyd, citado por NIESCHLAG et alii (9). Embora sejá tecnicamente possível separar as frações liberianas e lenhosas, sua viabilidade prática só deve ser possível para produzir papéis especiais. Para produção em grande escala de celulose e papel, deve-se considerar o conjunto líber-lenho. Neste caso, o comprimento intermediário das fibras foi estimado em $1,6 \mathrm{~mm}$.

As relações entre as dimensōes das fibras que influenciam as resistências físico-mecânicas do papel produzido, são apresentadas no quadro 5. Com diferenças marcantes entre os valores obtidos para as fibras do liber e do lenho, pode-se esperar que o processamento da mistura resultará em fibras com características dimensionais adiequadas para produzir papéis com boas propriedades de resistências físico-mecânicas.

A análise química do material em estudo (Quadro 6) mostrou, em comparação com as madeiras, menor teor de celulose e maior quantidade de materiais solúveis em água fria e quente, soda a $1 \%$ e álcool-benzeno. Os teores de celulose no liber e lenho foram, respectivamente, de $7,32 \%$ e $39,10 \%$. Esses dados evidenciam a pequena contribuição da celulose de fibras longas, provenientes do líber, nas caracteristicas finais do papel produzido. 
QUADRO 4. Dimensões das fibras liberianas e lenhosas dos residuos agrícolas da cultura da mamona (1)

\begin{tabular}{|c|c|c|c|c|c|c|c|c|}
\hline \multirow[b]{2}{*}{ Valor } & \multicolumn{4}{|c|}{ Fibras liberianas } & \multicolumn{4}{|c|}{ Fibras lenhosas } \\
\hline & $\begin{array}{l}\text { Compri- } \\
\text { mento }\end{array}$ & Largura & $\begin{array}{l}\text { Espes- } \\
\text { sura }\end{array}$ & Lúmen & $\begin{array}{l}\text { Compri- } \\
\text { mento }\end{array}$ & Largura & $\begin{array}{l}\text { Espes- } \\
\text { sura }\end{array}$ & Lümen \\
\hline & $\mathrm{mm}$ & micro & micro & micro & $\mathrm{mm}$ & micro & micro & micro \\
\hline Mínimo & 1,68 & 8,72 & 2,50 & 3,72 & 0,42 & $10 ; 72$ & 1,93 & 6,86 \\
\hline Médio & 5,51 & 21,08 & 5,41 & 10,26 & 0,87 & 19,93 & 3,42 & 13,09 \\
\hline Máximo & 18,20 & 42,56 & 12,21 & 18,14 & 1,96 & 33,14 & 7,07 & 19,00 \\
\hline $\mathbf{s}$ & 11,28 & - & 0,22 & 0,53 & 0,61 & - & 0,12 & 0,48 \\
\hline$s(\bar{x})$ & 0,79 & $\ldots$ & 0,02 & 0,05 & 0,04 & - & 0,01 & 0,04 \\
\hline c.v. $(\%)$ & 57,34 & $\ldots$ & 30,11 & 37,21 & 19,81 & - & 25,24 & 26,61 \\
\hline
\end{tabular}

(1) Média de 200 fibras. $s=$ desvio-padrão. $s(\vec{x})=$ erro-padrão da média. c.v. $=$ coeficiente de variação.

QUADRO 5. Relações entre as dimensōes das fibras liberianas e lenhosas dos resíduos agricolas da cultura da mamona

\begin{tabular}{|c|c|c|}
\hline Relações & $\begin{array}{l}\text { Fibras do } \\
\text { líber }\end{array}$ & $\begin{array}{c}\text { Fibras do } \\
\text { lenho }\end{array}$ \\
\hline Comprimento/espessura $\ldots \ldots \ldots \ldots \ldots \ldots \ldots \ldots$ & 1.018 & 254 \\
\hline Indice de infiltramento $\ldots \ldots \ldots \ldots \ldots \ldots \ldots \ldots$ & 261 & 43 \\
\hline Fração parede $(\%) \quad \ldots \ldots \ldots \ldots$ & 51 & 35 \\
\hline Coeficiente de flexibilidade $(\%) \ldots \ldots \ldots \ldots \ldots \ldots \ldots$ & 48 & 65 \\
\hline Relação de Mulsteph $\ldots \ldots \ldots \ldots \ldots \ldots \ldots$ & 0,77 & 0,57 \\
\hline Indice de Runkel $\ldots \ldots \ldots \ldots \ldots \ldots \ldots \ldots \ldots$ & 1,06 & 0,53 \\
\hline Nümero de Boiler $\ldots \ldots \ldots \ldots \ldots$ & 0,62 & 0,40 \\
\hline
\end{tabular}

QUADRO 6. Análise química dos resíduos agrícolas da cultura da mamona (1)

\begin{tabular}{|c|c|}
\hline Análise & Valor \\
\hline & $(\%)$ \\
\hline Solubilidade em água fria & 7,98 \\
\hline 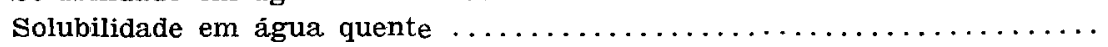 & 13,25 \\
\hline 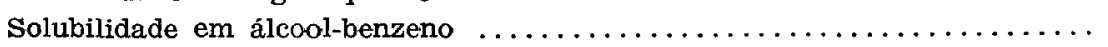 & 4,27 \\
\hline 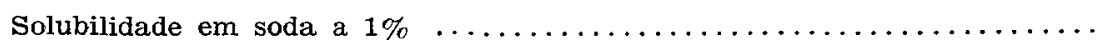 & 33,73 \\
\hline 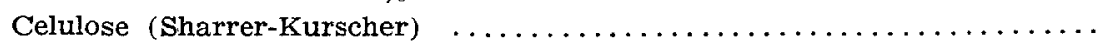 & 43,44 \\
\hline 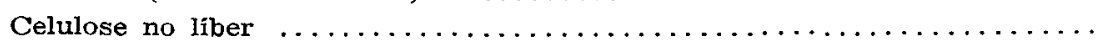 & 7,32 \\
\hline 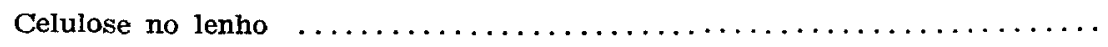 & 39,10 \\
\hline
\end{tabular}

(1) Médias de duas repetições. 
As características da celulose relacionadas com as condições de deslignificação (Quadro 7) foram semelhantes para os processos socia e sulfato, com exceção do Número Kappa e teor de lignina, que foram maiores na celulose e sulfato. Isso significa que a celulose soda apresenta maior facilidade de branqueamento.

QUADRO 7. Características das pastas celulósicas obtidas pelos processos soda e sulfato a partir dos resíduos agricolas da cultura da mamona (1)

\begin{tabular}{|c|c|c|c|}
\hline Caracteristicas & $\begin{array}{l}\text { Reagente } \\
\text { químico }\end{array}$ & $\begin{array}{l}\text { Processo } \\
\text { soda }\end{array}$ & $\begin{array}{c}\text { Processo } \\
\text { sulfato }\end{array}$ \\
\hline & $\%$ & & \\
\hline \multirow[t]{4}{*}{ Rendimento total (\%) } & 18 & $40,11 \mathrm{a}$ & $47,30 \mathrm{a}$ \\
\hline & 20 & 39,75 a & $41,13 \mathrm{a}$ \\
\hline & 22 & $38,08 \mathrm{a}$ & $40,33 a$ \\
\hline & & 39,32 a & $42,92 \mathrm{a}$ \\
\hline \multirow[t]{4}{*}{ Rendimento depurado $(\%)$} & 18 & 39,41 a & $38,57 \mathrm{a}$ \\
\hline & 20 & 39,17 a & $40,38 \mathrm{a}$ \\
\hline & 22 & 38,08 a & $40,23 \mathrm{a}$ \\
\hline & & 38,89 a & 39,73 a \\
\hline \multirow[t]{4}{*}{ Rejeitos $(\%)$} & 18 & $0,70 \mathrm{a}$ & $8,73 \mathrm{a}$ \\
\hline & 20 & $0,58 \mathrm{a}$ & $0,75 \mathrm{a}$ \\
\hline & 22 & 一 & $0,15 \mathrm{a}$ \\
\hline & & $0,64 \mathrm{a}$ & 3,21 a \\
\hline \multirow[t]{4}{*}{ Nümero Kappa $\left(n^{\circ}\right)$} & 18 & $26,62 \mathrm{a}$ & 49,16 a \\
\hline & 20 & $24,90 \mathrm{a}$ & $30,82 \mathrm{~b}$ \\
\hline & 22 & $23,60 \mathrm{a}$ & $24,35 \mathrm{~b}$ \\
\hline & & $25,04 \mathrm{~b}$ & 34,75 a \\
\hline \multirow[t]{4}{*}{ Lignina $(\%)$} & 18 & $3,91 \mathrm{a}$ & $7,37 \mathrm{a}$ \\
\hline & 20 & 3,73 a & $4,61 \mathrm{~b}$ \\
\hline & 22 & $3,53 \mathrm{a}$ & $3,64 \mathrm{~b}$ \\
\hline & & $3,72 \mathrm{~b}$ & 5,21 a \\
\hline
\end{tabular}

(1) Valores médios em uma mesma coluna, seguidos pela mesma letra, não diferem estatisticamente entre si, pelo teste de Duncan ao nivel de $5 \%$.

Em comparação com o processamento do eucalipto, esse material exige condições mais drásticas de deslignificação, o que está relacionado com a elevada quantidade de medula $(21,17 \%)$ presente na região cen- 
tral dos caules e ramos da mamona. A presença da fração medular influiu negativamente no rendimento de conversão e nc consumo de reagentes químicos, tanto no processo soda como no sulfato. Nos quadros 8 e 9 são apresentados os valores das propriedades físico-mecânicas das pastas soda e sulfato respectivamente.

QUADRO 8. Propriedades físico-mecânicas da celulose soda obtida a partir dos residuos fibrosos da cultura da mamona (1)

\begin{tabular}{|c|c|c|c|c|c|c|}
\hline \multirow{2}{*}{ Propriedade } & \multirow{2}{*}{ Soda $(\%)$} & \multicolumn{5}{|c|}{ Tempo de refinação (minutos) } \\
\hline & & 0 & 2,5 & 5,0 & 7,5 & 10,0 \\
\hline \multirow[t]{2}{*}{$\begin{array}{c}\text { Grau de refinação } \\
(\mathrm{SR})\end{array}$} & $\begin{array}{l}18 \\
20 \\
22\end{array}$ & $\begin{array}{l}28,0 \text { a } \\
31,0 \text { a } \\
29,5 \text { a }\end{array}$ & $\begin{array}{l}34,5 \text { b } \\
42,0 \text { a } \\
37,0 \text { b }\end{array}$ & $\begin{array}{ll}42,5 & b \\
50,0 & a \\
44,5 & b\end{array}$ & $\begin{array}{l}48,5 \text { a } \\
\mathbf{5 2 , 0} \text { a } \\
49,0 \text { a. }\end{array}$ & $\begin{array}{l}50,0 \text { a } \\
54,5 \text { a } \\
53,5 \text { a }\end{array}$ \\
\hline & & $29,5 \mathrm{c}$ & $37,8 \mathrm{~b}$ & 45,6 a. & $49,8 \mathrm{a}$ & \\
\hline \multirow[t]{2}{*}{$\begin{array}{l}\text { Comprimento de auto- } \\
\text {-ruptura }(\mathrm{km})\end{array}$} & $\begin{array}{l}18 \\
20 \\
22\end{array}$ & $\begin{array}{ll}1,95 & b \\
2,10 & b \\
2,80 & a\end{array}$ & $\begin{array}{ll}2,95 & b \\
3,95 & a \\
4,15 & a\end{array}$ & $\begin{array}{ll}4,10 & \mathrm{a} \\
4,30 & \mathrm{a} \\
4,45 & \mathrm{a}\end{array}$ & $\begin{array}{ll}4,15 & b \\
4,40 & b \\
5,00 & a\end{array}$ & $\begin{array}{ll}4,10 & b \\
4,55 & b \\
5,05 & a\end{array}$ \\
\hline & & $2,28 \mathrm{c}$ & $3,68 \mathrm{~b}$ & $4,28 a$ & 4,51 a & $4,56 \mathrm{a}$ \\
\hline \multirow[t]{2}{*}{ Alongamento $(\%)$} & $\begin{array}{l}18 \\
20 \\
22\end{array}$ & $\begin{array}{ll}0,35 & \mathrm{a} \\
0,45 & \mathrm{a} \\
0,55 & \mathrm{a}\end{array}$ & $\begin{array}{l}0,85 \text { a } \\
0,95 \text { a } \\
0,85 \text { a. }\end{array}$ & $\begin{array}{l}1,15 \mathrm{a} \\
1,05 \mathrm{a} \\
0,95 \mathrm{a}\end{array}$ & $\begin{array}{l}1,25 \mathrm{a} \\
1,10 \mathrm{~b} \\
1,25 \mathrm{a}\end{array}$ & $\begin{array}{ll}1,25 & a \\
1,35 & a \\
1,40 & a\end{array}$ \\
\hline & & $0,45 \mathrm{~d}$ & $0,86 \mathrm{c}$ & $1,05 \mathrm{~b}$ & $1,20 \mathrm{~b}$ & $1,33 \mathrm{a}$ \\
\hline \multirow[t]{2}{*}{ Indice de arrebentamento } & $\begin{array}{l}18 \\
20 \\
22\end{array}$ & $\begin{array}{ll}2,35 & \mathrm{a} \\
1,65 & \mathrm{~b} \\
2,25 & \mathrm{a}\end{array}$ & $\begin{array}{ll}3,15 & b \\
3,45 & b \\
3,85 & a\end{array}$ & $\begin{array}{ll}3,70 & b \\
3,90 & b \\
4,35 & a\end{array}$ & $\begin{array}{ll}4,05 & b \\
4,05 & b \\
4,45 & a\end{array}$ & $\begin{array}{l}4,55 \text { a } \\
4,25 \text { a } \\
4,60 \text { a }\end{array}$ \\
\hline & & $2,08 \mathrm{c}$ & $3,48 b$ & 3,98 a & 4,18 a & $4,46 a$ \\
\hline \multirow[t]{2}{*}{ Indice de rasgo } & $\begin{array}{l}18 \\
20 \\
22\end{array}$ & $\begin{array}{l}178,0 \text { a } \\
169,5 \text { a } \\
166,5 \text { a }\end{array}$ & $\begin{array}{l}171,5 \mathrm{a} \\
167,5 \mathrm{a} \\
165,0 \mathrm{a}\end{array}$ & $\begin{array}{l}181,0 \mathrm{a} \\
156,5 \mathrm{a} \\
167,0 \mathrm{a}\end{array}$ & $\begin{array}{l}170,0 \mathrm{a} \\
156,5 \mathrm{a} \\
162,0 \mathrm{a}\end{array}$ & $\begin{array}{l}174,0 \text { a } \\
164,5 \text { a } \\
169,5 \text { a }\end{array}$ \\
\hline & & $171,3 \mathrm{a}$ & 168,0 a & $168,1 \mathrm{a}$ & $162,8 \mathrm{a}$ & 169,3 a \\
\hline \multirow[t]{2}{*}{$\begin{array}{l}\text { Peso especifico } \\
\text { aparente }\left(\mathrm{g} / \mathrm{cm}^{3}\right)\end{array}$} & $\begin{array}{l}18 \\
20 \\
22\end{array}$ & $\begin{array}{ll}0,404 & a \\
0,459 & a \\
0,440 & a\end{array}$ & $\begin{array}{ll}0,501 & a \\
0,538 & a \\
0,542 & a\end{array}$ & $\begin{array}{ll}0,557 & a \\
0,564 & a \\
0,556 & a\end{array}$ & $\begin{array}{l}0,580 \mathrm{a} \\
0,609 \mathrm{a} \\
0,603 \mathrm{a}\end{array}$ & $\begin{array}{ll}0,593 & a \\
0,595 & a \\
0,587 & \end{array}$ \\
\hline & & $0,434 \mathrm{c}$ & $0,528 \mathrm{~b}$ & 0,562 a & 0,597 a & 0,591 \\
\hline
\end{tabular}

(1) Valores médios em uma mesma coluna, seguidos pela mesma letra, não diferem entre si, pelo teste de Duncan ao nível de $5 \%$. 
QUADRO 9. Propriedades físico-mecânicas da celulose sulfato, olutida a partir dos residuos finrosos da cultura da mamona (1)

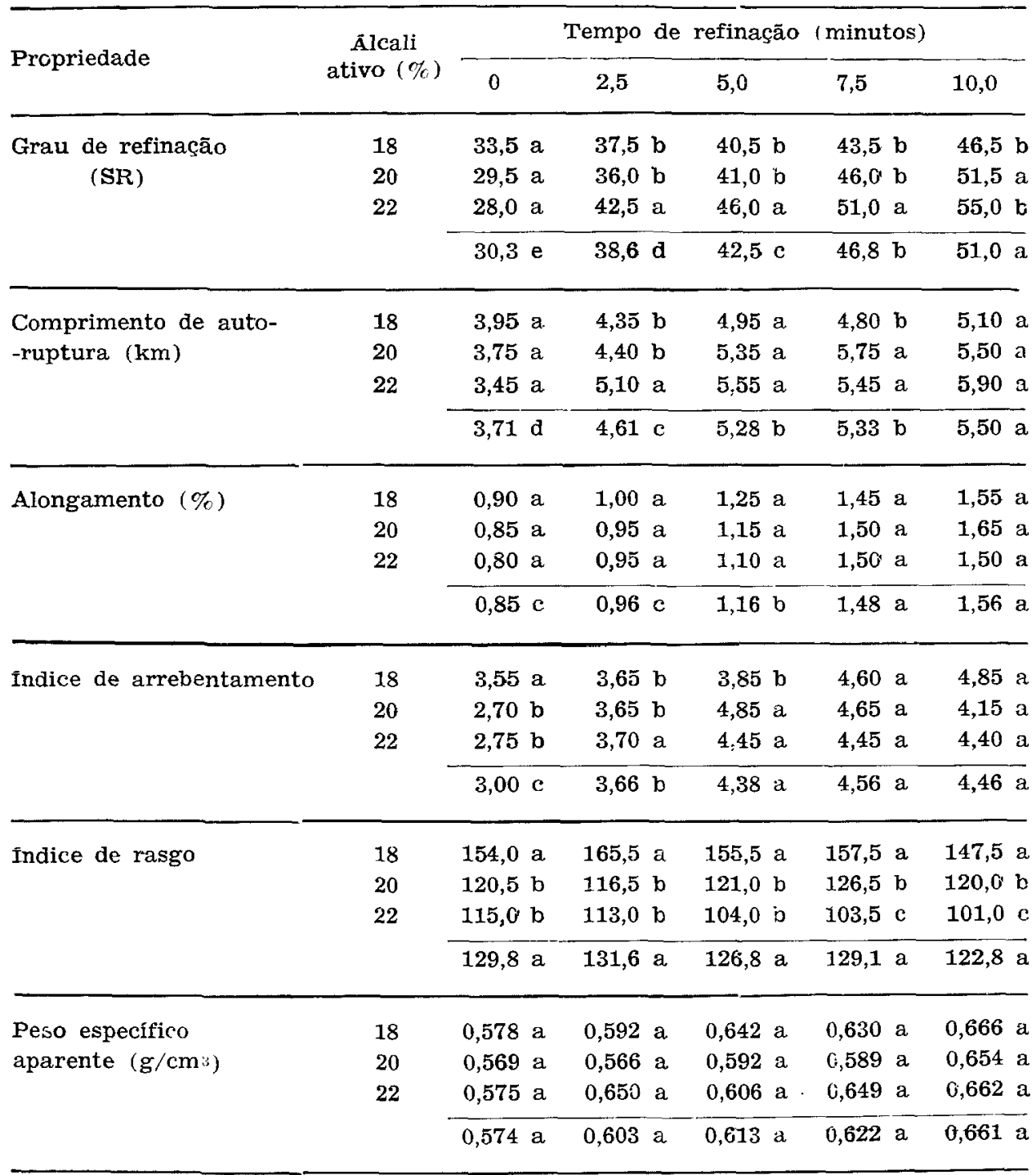

(1) Valores médios em uma mesma coluna, seguidos pela mesma letra, não diferem entre si, pelo teste de Duncan ao nível de $\mathbf{5} \%$.

Considerando um mesmo tempo de refinação (7,5 minutos) a celulose soda, em comparação com a sulfato, apresentou maior resistência ao rasgo e menor resistência ao comprimento de auto-ruptura. Essa 
variação está relacionada não com o processo de conversão em si, mas, principalmente, com a composição da mistura líber @ lenho em cada cozimento.

As resistências físico-mecânicas das pastas celulósicas obtidas (Quadros 8 e 9), evidenciam a possibilidade de produzir papel de razoável qualidade a partir desse resíduo agrícola. $O$ principal inconveniente dessa matéria-prima é seu elevado teor de medula, que exige em comparação às madeiras folhosas e resinosas maior concentraçãc de reagentes químicos, para se obter celulose com teores semelhantes de lignina residual. Por outro lado, a celulose obtida em comparação com a da madeira é facilmente refinada, consumindo menos energia.

\section{CONCLUS̃̃ES}

a) Nas condiçōes estudadas, a quantidade estimada de resíduos agrícolas da cultura da mamona (cultivar IAC-80) foi aproximadamente 17, 20 e 26t/ha, respectivamente, para as regiōes de Campinas, Tatuí e Tietê;

b) A densidade básica desse resíduo agricola foi baixa $\left(0,228 \mathrm{~g} / \mathrm{cm}^{3}\right)$ em comparação com as madeiras de eucalipto $\left(0,530 \mathrm{~g} / \mathrm{cm}^{3}\right)$ e pínus $\left(0,412 \mathrm{~g} / \mathrm{cm}^{3}\right)$;

c) As fraçōes liberianas e lenhosas dos caules e ramos da mamona fornecem, respectivamente, fibras longas $(5,51 \mathrm{~mm})$ e curtas $(0,87 \mathrm{~mm})$. O comprimento intermediário das fibras da mistura líber e lenho foi estimado em $1,6 \mathrm{~mm}$;

d) As características tecnológicas estudadas evidenciaram a possibilidade técnica de produzir celulose e papel a partir dos resíduos agricolas da cultura da mamona, ressaltando a influência negativa do seu alto teor de medula no rendimento em celulose e no consumo de reagentes químicos.

\section{SUMIMARY}

\section{DELIGNIFICATION OF AGRICULTURAL RESIDUES OF CASTOR BEAN CROP FOR PULP AND PAPER MAKING}

\footnotetext{
Agricultural residues of castor bean (cultivar IAC-80) crop were studied for pulp and paper making. The quantity of this fibrous material was estimated to be about 17, 20 and 26t/ha, respectively, for Campinas, Tatuí and Tietê regions, State of São Paulo, Brazil. The basic density of castor bean stalks and branchs are low $\left(0.228 \mathrm{~g} / \mathrm{cm}^{3}\right)$. The micrometrical studies indicated that bast and woody fibers were, respectively, long $(5.51 \mathrm{~mm})$ and short $(0.87 \mathrm{~mm})$. according to the technological characteristics studied this raw material can be utilized for pulp and paper manufacture. The main negative problem of this residue is the high content of the medular (pith) fraction. The presence of pith during the delignification reduces the pulp yield and increases the chemicals consumption.
} 


\section{REFERENCIAS BIBLIOGRAFICAS}

1. ASSOCIAÇÃO TÉCNICA BRASILEIRA DE CELULOSE R PAPEL. Normas de ensaios. São Paulo, 1970.

2. AZZINI, A.; SALGADO, A.L.B.; SAVY FILHO, A.; BANZATTO, N.V. Restos vegetais da cultura da mamona como matéria-prima para celulose. Bragantia, Campinas, 40:115-124, 1981.

3. BARRICHELO, L.E.G. \& BRITO, J.O. Potencialidade de espécies tropicais de eucalipto para produção de celulose sulfato branqueada. IPEF, Piracicaba, 13:9-37, 1976.

4. CHERKASSKY, H.H. Panorama geral do setor de papel e cclulose. In: SIMPOSIO REGIONAL DE PAPEL E CELULOSE DA ABCP, 3., Rio de Janeiro, $1981.29 p$.

5. COLODETTE, J.L. Estudo das características da madeira e da polpa Kraft da Cryptomeria japonica. In: CONGRESSO ANUAL DA ABCP, 15., São Paulo, 1982. Anais. v. 1, p.139-154.

6. FOELKEL, C.E.B.; BARRICHELO, L.E.G.; AMARAL, A.C.E.; VALLE, C.F. Variaçōes das características da madeira e propriedades da celulose sulfato de Pinus oocarpa em função da idade do povoamento florestal. IPEF, Piracicaba, 10:81-87, 1975 .

7. — ; BRASIL, M.A.M.; BARRICHELO, L.E.G. Métodos para determinação da densidade básica de cavacos para coníferas e folhosas. IPEF, Piracicaba, 2/3:65-75, 1971.

8. MILANEZ, A.C. \& FOELKEL, C.E.B. Processos de deslignificação com oxigênio para produção de celulose de eucalipto. In: CONGRESSO ANUAL DA ABCP, 14., São Paulo, 1981. Anais. v. 1, p.37-110.

9. NIESCHLAG, H.J.; NELSON, G.H.; WOLFF, I.A.; PERDLE JR., R.F. A search for a new fiber crops. TAPPI, 43:193-201, 1960.

10. PROGNóSTICO. São Paulo, Instituto de Economia Agrícola, 1983/1984.

11. SAGRISTÂ, J.N. Temas de la fabricación del papel. Alcoy, Espanha, Editorial Marfil, S.A., 1970. 431p. 